\title{
Comparative immunogenicity assessment of biosimilars
}

\author{
Thomas Schreitmüller ${ }^{1}$, Bettina Barton², Artem Zharkov² \& Georgios Bakalos*,2,3 \\ ${ }^{1}$ Roche Pharma Technical Operations, Regulatory Policy, F. Hoffmann-La Roche Ltd, Basel, Switzerland \\ ${ }^{2}$ Global Product Development Medical Affairs, F. Hoffmann-La Roche Ltd, Basel, Switzerland \\ ${ }^{3}$ Department of Biomathematics, University of Thessaly School of Medicine, Larisa, Greece \\ *Author for correspondence: Tel.: +41 6168 80907; George.bakalos@roche.com
}

The first anticancer biosimilars have entered clinical use, with many others under clinical development. Like all biologics, biosimilars may elicit unwanted immune responses that can significantly impact clinical efficacy and safety. Head-to-head immunogenicity assessment of biosimilars and their reference biologics should, therefore, be a critical component of a biosimilar's clinical development program. Various bioanalytical platforms may be used to detect and characterize immune responses, each having relative strengths and weaknesses. To fully recognize the clinical relevance of such data, regulators must be able to interpret immunogenicity results in an assay-specific context as well as in perspective of clinical pharmacology, efficacy and safety. Herein, we discuss current challenges imposed by global regulatory requirements for immunogenicity assessment of biosimilars.

First draft submitted: 23 July 2018; Accepted for publication: 13 September 2018; Published online: 3 October 2018

Keywords: antidrug antibodies $\bullet$ biosimilarity $\bullet$ biosimilars $\bullet$ immunoassay $\bullet$ immunogenicity

Over the past 20 years, biologic medicinal products (biologics) have transformed treatment landscapes worldwide for patients with hematological or solid malignancies. Today, as data exclusivity periods of first wave biologics approach expiration/have expired, several biosimilar products (i.e., biologics that are considered to be similar in terms of quality, safety and efficacy to an approved 'reference' biologic) are being developed or have already been approved for human use [1].

Like all biologics, biosimilars are structurally complex proteins that are typically manufactured using genetically engineered animal, bacterial or plant cell culture systems. As a consequence of this molecular complexity and the proprietary nature of the manufacturing process, which will inevitably result in the use of different host cell lines and expression systems as well as related differences in manufacturing conditions, it is not possible to manufacture exact copies of a reference biologic [2]. Due to the potential product differences, it follows directly that regulatory approval of biosimilars (in the majority of global jurisdictions) is granted on the basis of rigorous quality, nonclinical and clinical head-to-head assessments that demonstrate 'biosimilarity' to the reference biologic [3-5]. As part of this approval pathway, the clinical immunogenicity profile of the biosimilar must be investigated in a comparative manner with the reference biologic.

When administered to patients, all therapeutic proteins have the potential to induce an unwanted immune response (i.e., to stimulate the formation of antidrug antibodies [ADAs]). The impact of immune responses can range from no apparent effect to changes in pharmacokinetics (PK), loss of effect and serious adverse events [6-8]. Furthermore, the immunogenicity profile of a biologic can be significantly altered by even small differences in its manufacturing process that are accompanied by a change in product attributes, as well as differences in dosing schedules, administration routes or patient populations [3,6,7,9-11]. For instance, during clinical development of Omnitrope $^{\circledR}$ (Sandoz Inc., NJ, USA; a somatropin biosimilar), high levels of host cell protein in a batch used for Phase III studies were associated with up to $60 \%$ of patients developing antigrowth hormone antibodies (vs $2 \%$ of patients treated with the reference biologic) with no apparent impact on efficacy [12]. At the other end of the scale, several cases of neutralizing anti-erythropoietin antibody development and subsequent adverse events (pure red cell aplasia) have been reported following subcutaneous administration of erythropoietin biologics from different

Future Medicine 
manufacturers in patients with chronic renal failure; this effect has been attributed to the route of administration as well as product-related factors, such as changes in formulation and in container closure systems $[2,7,13,14]$.

Assessment of immunogenicity is, therefore, of critical importance when establishing the safety profile of all biologics, and head-to-head assessment of immunogenicity with the reference product, ideally demonstrating similarity, is considered a key component of a biosimilar's clinical development program. In this review, we discuss current regulatory guidance and critically evaluate bioanalytical methods for judgement of comparable immunogenicity between biosimilars and their reference products.

\section{Current regulatory guidance for comparative immunogenicity assessments}

Guidelines for the development of biosimilars have been issued by the EMA, WHO and US FDA [4,5,15-21]. Over the past decade, many more countries have also implemented national guidance documents based on the same principles as outlined in EMA, WHO and FDA guidances (e.g., Canada, Japan, Brazil, South Africa, the Republic of Korea and many others) [22].

According to these guidelines, the development of biosimilars involves a stepwise demonstration of similarity to a reference biologic, with regulatory approval based on the 'totality of evidence' provided by head-to-head comparisons of analytical, nonclinical and clinical data $[1,22,23]$. At each step of the biosimilar's development, the sponsor can identify any differences between the biosimilar and reference biologic that contribute to 'residual uncertainties' about product similarity and tailor the scope and extent of subsequent studies accordingly. Thus, provided analytical data demonstrate robust physicochemical and biological similarity, a biosimilar candidate may be granted regulatory approval based on abbreviated nonclinical and clinical data packages [22].

As part of this development pathway, head-to-head clinical immunogenicity testing in an adequately sensitive study population (i.e., the patient population in which the study biologics are most likely to elicit an immune response) is recommended by the EMA, WHO and FDA as a key criterion for the regulatory evaluation of biosimilarity [3,5,24-26]. To assess clinical immunogenicity, a fully-validated, tiered approach for detection of ADAs is recommended. The four main assessment stages involve: ADA screening, ADA confirmation assays, ADA characterization and titration, and assessment of neutralizing capacity. Each of these stages may be fulfilled using a variety of bioanalytical platforms, and results of these assays should be considered as part of an integrated pharmacology, safety and efficacy analysis, critical for elucidating the clinical relevance of immunogenicity data [2628].

While the need for comparative immunogenicity assessments is accepted among regulators, of note, regulatory opinions on what constitutes a clinically meaningful difference in immunogenicity can diverge. This matter is illustrated by the case example of Flixabi ${ }^{\circledR}$ (Samsung Bioepis UK Ltd, Middlesex, UK), an infliximab biosimilar which was issued a positive opinion by the EMA Committee for Medicinal Products for Human Use for all licensed indications of the reference biologic, Remicade ${ }^{\circledR}$ (Janssen Biotech, Inc., PA, USA), in April 2016 [29,30]. EU approval was granted although a substantial number of committee members considered the benefit/risk ratio negative on account of higher ADA rates observed in Flixabi versus Remicade treated subjects in Phase I and Phase III clinical equivalence studies (Phase I: $9.5 \%$ difference by study day 71; Phase III: 5-12\% difference at individual timepoints). The committee members noted that the higher ADA rates offered a potential explanation for the lower (but within prespecified equivalence margins) efficacy of Flixabi versus Remicade. Additionally, the sensitivity of the Phase III population (patients with rheumatoid arthritis [RA] in receipt of immunomodulatory therapy) was questioned. Notably, limitations of the immunoassay could not be ruled out as the cause of variation in observed ADA rates, highlighting the need for further standardization of both bioanalytical approaches and regulatory definitions of similar immunogenicity.

\section{Variability in immunogenicity assays}

Immunogenicity data are highly dependent on the assay used to measure ADAs (including reagents, standards, validation criteria, etc.). Furthermore, immunoassays for screening and confirming ADAs can be conducted using a variety of formats and detection systems, each of which has relative strengths and weaknesses (Table 1; Figure 1) $[11,27,28]$. While there is no single assay format suitable for assessing the immunogenicity of all biologics, regardless of the method selected, all assays must be thoroughly validated according to parameters that include cut-point, sensitivity, specificity, selectivity, precision, dilution linearity and limit of drug tolerance (see Table 2 for definitions) [26,28,31-34]. However, because human ADAs are of limited availability, international reference sera/standards for immunoassay validation and calibration are generally unattainable, with the exception of the 
Table 1. Strengths and weaknesses of immunoassays.

\begin{tabular}{|c|c|c|c|}
\hline Assay & Description & Strengths & Weaknesses \\
\hline \multicolumn{4}{|c|}{ ADA screening and confirmatory assays ${ }^{\dagger}$} \\
\hline ELISA & $\begin{array}{l}\text { ADAs captured by immobilized biologic } \\
\text { and detected using a colorimetric labeled } \\
\text { antibody }\end{array}$ & $\begin{array}{l}\text { - Convenient (ease of use) } \\
\text { - High-throughput } \\
\text { - Inexpensive }\end{array}$ & $\begin{array}{l}\text { - High chance of false-positive results } \\
\text { - Loss of low-affinity ADAs during washes } \\
\text { - High background } \\
\text { - Not suitable for detection of ADAs } \\
\text { against mAbs }\end{array}$ \\
\hline Bridging ELISA & $\begin{array}{l}\text { ADAs captured by immobilized biologic } \\
\text { and detected with colorimetric labeled } \\
\text { biologic }\end{array}$ & $\begin{array}{l}\text { - More specific and selective than ELISA } \\
\text { - Can be used where the biologic is a mAb } \\
\text { - High-throughput }\end{array}$ & - Loss of low-affinity ADAs during washes \\
\hline $\mathrm{ECL}$ & $\begin{array}{l}\text { ELISA or Bridging ELISA technique with a } \\
\text { ruthenium-conjugated antibody or biologic } \\
\text { for detection, respectively }\end{array}$ & $\begin{array}{l}\text { - Increased sensitivity vs. colorimetric } \\
\text { conjugates } \\
\text { - Bridging format can be used where the } \\
\text { biologic is a mAb } \\
\text { - High-throughput }\end{array}$ & $\begin{array}{l}\text { - Reagents can be expensive } \\
\text { - Loss of low-affinity ADAs during washes }\end{array}$ \\
\hline RIA & $\begin{array}{l}\text { ADAs captured on protein } \mathrm{A} \text { beads and } \\
\text { detected with a radiolabeled antibody or } \\
\text { biologic }\end{array}$ & $\begin{array}{l}\text { - More sensitive than ELISA } \\
\text { - Moderate throughput } \\
\text { - Inexpensive }\end{array}$ & $\begin{array}{l}\text { - Radioactivity may deter investigators } \\
\text { - Reagents require specific equipment and } \\
\text { safety measures } \\
\text { - Loss of low-affinity ADAs during washes }\end{array}$ \\
\hline SPR & $\begin{array}{l}\text { Sensor with immobilized biologic detects } \\
\text { changes in mass following ADA binding }\end{array}$ & $\begin{array}{l}\text { - Can detect low-affinity and rapidly } \\
\text { dissociating ADAs } \\
\text { - Can be used to determine ADA isotype }\end{array}$ & $\begin{array}{l}\text { - May be less sensitive than other assays } \\
\text { - Not for high-throughput } \\
\text { - Expensive equipment and reagents }\end{array}$ \\
\hline \multicolumn{4}{|l|}{ NAb detection } \\
\hline Cell-based assay & $\begin{array}{l}\text { Measures neutralization of cell responses } \\
\text { using relevant cell lines }\end{array}$ & $\begin{array}{l}\text { - Provides a functional biological readout } \\
\text { - May be the preferred NAb assay of } \\
\text { regulatory authorities }\end{array}$ & $\begin{array}{l}\text { - High variability } \\
\text { - Matrix interference } \\
\text { - Low sensitivity } \\
\text { - Low free drug tolerance } \\
\text { - Longer assay time than ligand binding } \\
\text { assays }\end{array}$ \\
\hline Ligand binding assay & $\begin{array}{l}\text { Measures neutralization of drug to target } \\
\text { (e.g.. cellular receptor) binding }\end{array}$ & $\begin{array}{l}\text { - Easier to implement and more sensitive } \\
\text { and drug-tolerant than cell-based assays } \\
\text { - Different detection systems (e.g., ELISA } \\
\text { and ECL) can be used }\end{array}$ & $\begin{array}{l}\text { - Does not provide the functional readout } \\
\text { of cell-based assays }\end{array}$ \\
\hline \multicolumn{4}{|c|}{$\begin{array}{l}\text { †ADA confirmatory assays employ the same design as screening assays but involve the addition of competing, unlabeled reference or biosimilar drug to measure response } \\
\text { inhibition. } \\
\text { ADA: Antidrug antibody; ECL: Electrochemiluminescence; ELISA: Enzyme-linked immunosorbent assay; mAb: Monoclonal antibody; Nab: Neutralizing antibody; RIA: Radioim- } \\
\text { munoassay; SPR: Surface plasmon resonance. }\end{array}$} \\
\hline
\end{tabular}

\section{Table 2. Glossary of immunoassay validation parameters.}

\begin{tabular}{|ll|}
\hline Validation parameter & $\begin{array}{l}\text { Definition } \\
\text { Cut-point }\end{array}$ \\
\begin{tabular}{|l} 
The threshold at which a sample is categorized as ADA-positive/negative. Cut-point should be determined, based on negative control \\
signals, before commencing clinical trials
\end{tabular} \\
\hline Sensitivity & $\begin{array}{l}\text { The lowest ADA concentration that consistently produces a positive signal or a signal equal to the cut-point. Sensitivity is dependent } \\
\text { on the binding affinity of the positive control }\end{array}$ \\
\hline Selectivity & $\begin{array}{l}\text { The ability of the assay to detect biologic-specific ADAs in a matrix, like plasma, that may contain interfering substances. Selectivity } \\
\text { can be assessed by measuring responses in drug-naive negative control samples } \\
\text { Of note, target molecules of the biologic (e.g., target antigens of mAbs) can interfere with immunoassays and reduce selectivity }\end{array}$ \\
\hline Precision & The ability of the assay to produce consistent results between runs (i.e., the measure of intra- and inter-assay variability) \\
\hline Dilution linearity & $\begin{array}{l}\text { The ability of the assay to maintain a linear, positive relationship between the ADA concentration and the signal. Samples with ADA } \\
\text { concentrations above the linear range of detection should be analyzed using the appropriate dilutions }\end{array}$ \\
\hline Specificity & $\begin{array}{l}\text { The ability of the assay method to detect ADAs that bind to the biologic but not to other assay components (e.g., plates) or reagents. } \\
\text { Specificity can be assessed by demonstrating that binding is blocked by excess unlabeled biologic }\end{array}$ \\
\hline Drug tolerance limit & The concentration of biologic that blocks ADA detection in positive control samples \\
\hline ADA: Antidrug antibody; mAb: Monoclonal antibody.
\end{tabular}

WHO erythropoietin antibody reference panel (the only international ADA standard currently available, consisting of nine human monoclonal antibodies against erythropoietin with various characteristics) [35]. Furthermore, because human ADAs are complex analytes (i.e., they are usually polyclonal, bind to different domains of the biologic and have variable isotypes and binding affinities) reference sera/standards may not accurately represent ADA heterogeneity within a study population $[11,28,31]$. As such, there is currently no consensus among experts regarding 


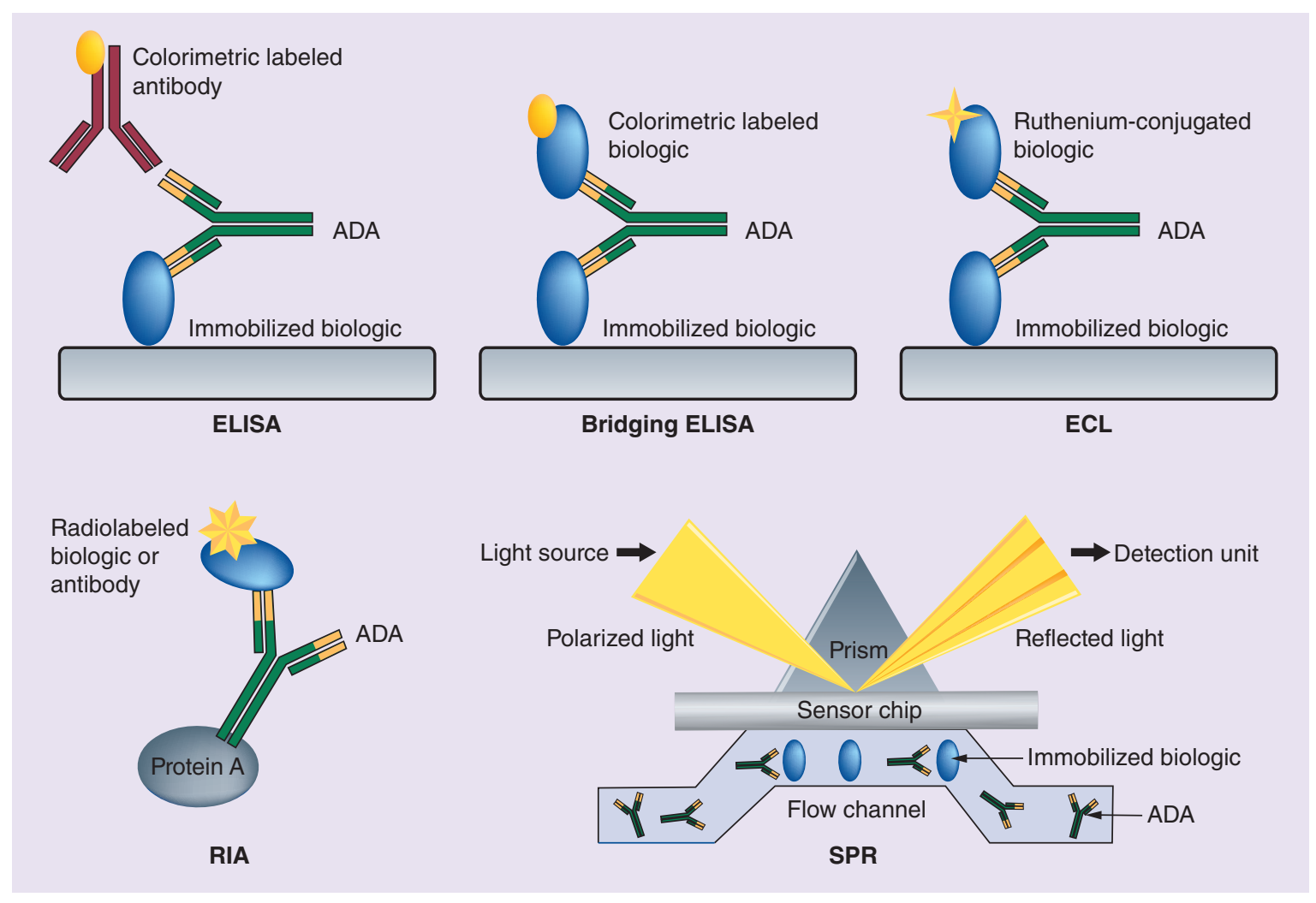

Figure 1. Antidrug antibody detection assays. Refer to Table 1 for specific assay descriptions. ADA: Antidrug antibody; ECL: Electrochemiluminescence; ELISA: Enzyme-linked immunosorbent assay; RIA: Radioimmunoassay; SPR: Surface plasmon resonance.

the implementation of reference standards, and several key assay parameters (e.g., sensitivity and limit of drug tolerance) are relative values determined by the choice of surrogate positive control samples, often generated via hyperimmunization of animals or phage display $[11,31,36]$. As a result, the vast majority of immunoassays used for detecting $\mathrm{ADAs}$ currently cannot be universally validated nor calibrated, limiting the value of comparisons between different studies as well as the ability to provide meaningful, quantitative data $[11,28,31,36,37]$.

Additionally, in recent years, more sensitive and specific assays have been developed. For example, as ADAs bound to excess biologic in patient serum samples usually cannot be detected by traditional ADA assays, novel 'drugtolerant' assays (e.g., acid-dissociation radioimmunoassay) have been established. In such assays, complexes of ADA and the biologic drug are dissociated prior to ADA detection, minimizing the possibility for false-negative results [28]. As such, modern immunoassays often provide higher readouts compared with traditional assay formats, and historic data cannot be used for comparative purposes or for establishing margins of clinically acceptable difference in ADA rates between biosimilars and reference products. The increasing sensitivity of modern immunoassays is highlighted by the case example of adalimumab (a TNF- $\alpha$ inhibitor approved for treatment of various inflammatory disease), where ADA rates in patients with RA have been reported in the range of $1-66 \%$ depending on the choice of assay [28]. Similarly, the US product labeling of etanercept (also a TNF- $\alpha$ inhibitor) sets ADA rates at up to 6\% in patients with RA, yet recent data from Emery et al. reported a rate of $13.1 \%$, which has been attributed to the high sensitivity and drug tolerance of the chosen electrochemiluminescence (ECL) assay [38-42]. Given the limitations of data comparisons across studies, the immunogenicity of a biosimilar must instead be investigated using head-to-head comparative assays with the reference biologic.

In addition to the choice of screening and confirmatory assays, multiple options for detection of neutralizing antibodies (NAbs) in ADA positive samples also exist [43,44]. Depending on the biologic's mechanism of action (MoA), the selected assay may be cell-based or non-cell-based (Table 1). While the non-cell-based (competitive ligand binding) approach offers greater precision and sensitivity and an easier set up in terms of establishing validation parameters, these assays are considered appropriate only when the biologic's MoA involves blocking of a soluble 
target or cellular receptor $[3,11,26,44]$. Additionally, cell-based approaches may be favored by certain regulatory authorities as they may offer better insight into the functional and biological activity of the product $[11,26,44]$. However, cell-based experiments should not be considered the default option if sufficient sensitivity, precision and robustness cannot be achieved; in these situations, further dialogue with regulators may be necessary to define an appropriate non-cell-based method [3,26].

Similar to ADA assays, NAb assays are validated according to assay-specific control signals [44]. Additionally, during the development of the reference product, the NAb assay is likely to have been developed according to key MoAs that contribute most therapeutic efficacy as well as contemporaneous technology limitations; yet, with advancements in technology and knowledge of biological processes, it is accepted that NAb assays for biosimilars can be based on a distinct MoA, which should be a major efficacy contributor but also the most sensitive MoA for detecting differences between products [44]. As such, historic NAb data are also of limited value when assessing a biosimilar's immunogenicity profile.

Currently, no specific regulatory guidelines are available for the conduct of NAb confirmatory or titration assays as it is widely accepted that the NAb assay is a qualitative (positive or negative) experiment used for further characterization of ADA assays, which already include a confirmatory step. However, if unexpected or nonspecific responses are observed during qualitative experiments, further practical considerations for NAb confirmation (e.g., use of an agonist molecule to assess signal inhibition) or titration experiments will be required [44].

\section{Influence of dosing, sampling \& patient populations}

Aside from the assay that is used to detect ADAs, there are additional factors to consider which can influence immunogenicity data, such as the dosing schedule, the timing of clinical sample collection for the analyses and patient-related factors. As highlighted by the case of infliximab treatment in patients with Crohn's disease, incidence of ADAs may increase when using an episodic versus regular dosing schedule (30 vs $8 \%$ of patients, respectively) [9]. Additionally, sampling should account for temporal ADA formation patterns. For instance, ADA formation may occur rapidly, gradually or transiently, and sampling schedules should be designed to capture this information accordingly. As such, it is generally recommended that samples are taken more frequently during early use of the product (i.e., when an immune response is more likely to occur), and post-treatment sampling should be long enough to determine the persistence of immune responses [17,25]. As recommended in EMA guidance, sampling should also take into account product half-life and drug tolerance of the ADA assay [3]. Differences in ADA rates can also occur among patient populations, e.g., in patients with Crohn's disease who received infliximab with versus without concomitant immunomodulators ( 46 vs $73 \%$, respectively) [3,9]. Head-to-head comparisons of ADA rates between biosimilars and their reference products must therefore be performed in adequately sensitive patient populations, using an appropriate dosing and sampling schedule. It is particularly important for regulators and sponsors to consider these aspects of study design when evaluating the potential to extrapolate immunogenicity data to other indications, under which patient immune status and dosing schedules may vary. Furthermore, as a biologic may have a unique MoA in different patient populations, additional data may be required to demonstrate that the formation of neutralizing antibodies is similar between patients treated with the reference biologic versus the biosimilar in all intended therapeutic indications $[4,17]$. As specified in current regulatory guidance, extrapolation is not self-evident and always requires scientific justification $[4,5,17]$.

\section{Limitations of comparative immunogenicity assessments}

Immunogenicity assessment strategies for biosimilars are established on a case-by-case basis. The aim of the assessment is to characterize potential differences between the biosimilar candidate and the reference product in terms of the incidence and severity of human immune responses. To achieve this aim, bioanalytical assays used to determine similar immunogenicity must have capacity to detect both biosimilar and reference product ADAs (or NAbs if assessing neutralization) in a comparable manner. However, a general approach for comparative assessment of immunogenicity is not well defined, nor is there full consensus among experts [28,37]. As such, the use of a two-assay or one-assay approach for comparing ADA rates remains a matter of debate.

The two-assay approach uses two parallel assays, one with reagents that detect ADAs against the reference product and one with reagents for detection of ADAs against the biosimilar (Figure 2A) [28,45]. While two separately optimized assays may offer better representation of the individual immunogenicity profiles of the biosimilar and reference product, this approach is challenging from an operational perspective as samples either must be run twice (once with each assay) or, alternatively, unblinded [37,44]. Additionally, the use of separate assays/reagents can be expected 
(A)

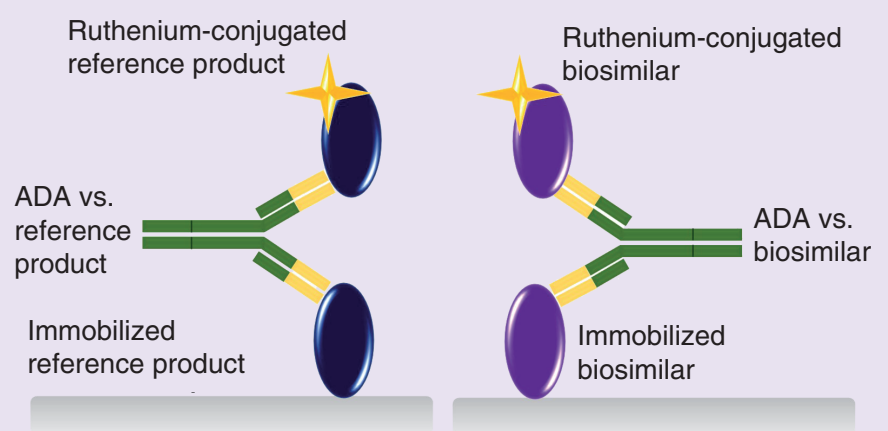

(B)

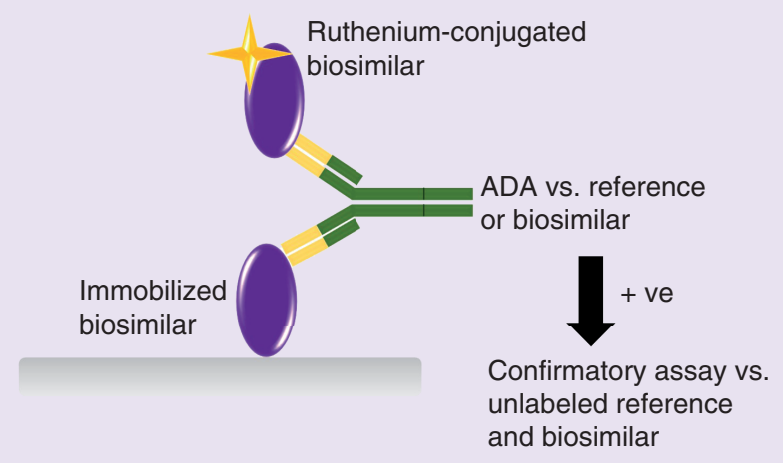

Figure 2. Head-to-head comparative immunoassays. (A) Two-assay ECL approach. (B) One-assay ECL approach. ADA: Antidrug antibody; ECL: Electrochemiluminescence.

to decrease reliability of data comparisons due to inter-assay variability. Comparable inter-assay performance and sensitivity must therefore be demonstrated to employ a two-assay approach.

In contrast, the one-assay approach uses a single assay to minimize bioanalytical bias. ADA binding is first measured in a screening assay that uses biosimilar reagents only; a confirmatory step is then implemented to assess inhibition of binding using both unlabeled reference and biosimilar product as competing antigens (Figure 2B) $[28,45]$. With this approach, detection of biosimilar ADAs is optimized and inter-assay variability minimized, but less information concerning immunogenicity of the reference product is obtained. However, as the generation of new information concerning the reference product is not the purpose of comparative immunogenicity assessment, a validated one-assay approach, rather than a two-assay approach, is generally recommended by regulators and experts in the bioanalytical industry $[28,37,44]$.

Nonetheless, if a one-assay approach is chosen, additional experiments to confirm the suitability of the assay to detect both reference product and biosimilar ADAs are required [37]. While several methods for substantiating the one-assay approach have been proposed (e.g., using increasing concentrations of biosimilar and reference biologic to generate and compare positive control signal inhibition curves), no standardized technique or regulatory guidance is currently in place to direct such experiments [37,45-48]. Furthermore, there is little unanimity on whether one or two positive controls should be used to validate the assay (i.e., antibiosimilar only or both antibiosimilar and antireference product controls) nor on the stage of assay development at which these experiments should be implemented [37].

Notably, the use of one or two positive controls is a central issue for the validation of both the one-assay and two-assay approach. While the use of both positive controls may be considered the more conservative option for a one-assay set up, it should be noted that no two positive controls can have the same binding affinity, even when generated in the same species according to the same immunization schedule [31,37]. As such, use of multiple controls 
can introduce analytical complexities, such as two different sensitivities and, subsequently, two sets of acceptance criteria [37]. As discussed in a publication by Islam et al., a single antibiosimilar positive control may be used for a two-assay set up, allowing for a more uniform establishment of validation parameters [36]. However, if structural differences (e.g., significant differences in glycosylation) between the biosimilar and reference product are identified or expected, use of both antibiosimilar and antireference positive controls may be necessary to better represent potential immune responses against each biologic [36]. Nonetheless, the need to evenly represent ADAs against both the originator and biosimilar using two positive controls can be questioned, as no surrogate positive control can be expected to mimic the full spectrum of immune responses observed in patients [37]. As such, many experts would agree that one positive control is sufficient as controls should only be perceived as a means to demonstrate system suitability [37].

Due to the wide range of factors that can prevent detection of ADAs (ranging from assay design to sampling schedules), a lack of difference in detected ADAs cannot automatically exclude the potential existence of clinically meaningful differences in immunogenicity. In line with regulatory recommendations, ADA rates must therefore be considered in integrated analyses of clinical pharmacology, safety and efficacy. Additionally, subgroup efficacy and safety analyses (in patients with and without immune responses) may be recommended by regulatory authorities [17]. However, given the reduced clinical data requirements for approval of biosimilars, the ability to place ADA rates into a clinically meaningful context and to perform subgroup analyses on pre-approval data may be limited. Collection of postmarketing data is, therefore, recommended by regulators.

\section{Postmarketing immunogenicity assessment}

Results of short-term immunogenicity analyses may not reflect real-world experience with biologics, including biosimilars. In particular, rare ADA-related adverse events may not to be detected in the premarketing phase due to the limited size of the population exposed and the greater scrutiny of patient care in the clinical trial setting. As such, EMA, WHO and FDA guidelines recommend consideration of immunogenicity in pharmacovigilance and risk management plans of biologic medicinal products $[4,5,17]$.

Continuous product traceability by ensuring unique product identification is critical for the successful management of postmarketing surveillance activities. To accurately report and attribute adverse drug reactions (ADRs) to the correct biologic, physicians must know which particular product was given to a patient and must be able to differentiate safety signals between products or among different batches of the same product. To ensure correct attribution of ADRs in the postmarketing setting, regulators have responded to concerns regarding use of the same international nonproprietary name (INN) for biosimilars and their reference biologics by issuing mandates on nomenclature conventions [49,50]. To clearly distinguish between products, the FDA require a unique four-letter suffix in the INN of all biologics, including biosimilars, and the Japanese Pharmaceuticals and Medical Devices Agency specify that the nonproprietary names of biosimilars should contain the INN of the reference product, plus 'biosimilar' and a number indicating the order in which the biosimilar was approved in Japan [51]. The EMA on the other hand indicate that biosimilars should use the same INN as the originator but state that the capture of brand name and batch number during ADR reporting should be ensured to be able to distinguish between products.

However, for these measures to be effective, appropriate systems must be in place to ensure that physicians, pharmacists and dispensaries are aware of reporting obligations. As suggested in a recent survey of Dutch hospital physicians and pharmacists, reporting of biologic brand names may not be consistent, and only $76 \%$ of European ADR reports for biologics contained brand names [52].

Notably, the stringent definitions and regulatory requirements related to the approval and pharmacovigilance of biologics, including biosimilars, as stipulated by relevant bodies such as the EMA, the FDA and the WHO are not equally applied globally. Therefore, ADRs reported for 'follow-on' biologics that did not undergo the same stringent regulatory evaluation (also called 'noncomparable biologics') may not be representative of biologics approved in highly regulated markets [23,53]. A clear distinction of safety profiles between products approved in these jurisdictions is essential. However, in resource-limited settings, it may be challenging to increase the capacity of regulatory authorities to achieve a rigorous oversight of biologics throughout their life-cycle [54].

Another key consideration for the real-world setting is the possibility for unwanted immune responses to occur when clinically stable patients who are treated with a reference biologic are switched to treatment with a biosimilar (or vice versa). As clinical switching studies are not a prerequisite for regulatory approval of biologics, the type and amount of switching-related immunogenicity data submitted in the premarketing phase will be limited or nonexistent [55]. Thus, physicians may be confronted with residual uncertainty when assessing the potential impact 
of switching in their patient populations [55]. Furthermore, the availability of switching data may vary according to indication, with switching data for therapeutic monoclonal antibodies in the oncology setting being generally scarce [56]. Accordingly, further clinical data from well-designed switching studies, which take into account the above-mentioned criteria in study design and test systems to allow for reliable immunogenicity assessment, are required to support physicians' decision making in this important context [56].

\section{Conclusion}

To conclude, ADA assay results need to be understood in the context of the assay that was used and its validation. Regulatory agencies must have in-depth understanding of the merits and limitations of individual immunogenicity assessments to appropriately interpret immunogenicity data generated in the prelicensure studies, and physicians should be aware of the relevance of these data for their specific patient populations. Further guidance from regulatory authorities on the details of comparative assay validation should facilitate the standardization of bioanalytical approaches and help to harmonize global definitions of similar immunogenicity.

\section{Executive summary}

- When administered to patients, all biologics, including biosimilars, may induce unwanted immune responses (e.g., the formation of antidrug antibodies [ADAs]), the impact of which can range from no apparent effect to severe adverse events.

Current regulatory guidance for comparative immunogenicity assessments

- Head-to-head clinical immunogenicity testing of biosimilars versus the reference biologic is recommended by regulators as a key criterion for demonstrating 'biosimilarity' in the premarketing setting.

- A tiered approach involving ADA screening assays, confirmatory assays, characterization and assessment of neutralizing capacity is recommended.

Variability in immunogenicity assays

- Immunoassays for detecting and characterizing ADAs can be conducted using a variety of formats, all of which have strengths and weaknesses and must be validated according to parameters such as sensitivity and limit of drug tolerance.

- The current lack of suitable reference standards means that these validation parameters cannot be universally calibrated. Considering that modern immunoassays have shown improved sensitivity and drug tolerance, immunogenicity comparisons across studies are of limited value.

- Immunogenicity of biosimilars must, therefore, be assessed in a head-to-head manner as per regulatory requirements.

Influence of dosing, sampling \& patient populations

- In addition to the choice of assay, dosing schedules, timing of clinical sample collection and patient immune status can influence the detectability of ADAs.

- Regulators must evaluate these aspects of study design carefully when considering extrapolation of immunogenicity data to other patient populations with different dosing schedules.

Limitations of comparative immunogenicity assessments

- A general approach for head-to-head assessment of immunogenicity is not well defined, and debates concerning use of a one-assay or two-assay set-up are ongoing.

- While the one-assay set-up is emerging as the preferred option among regulators, there is currently no standardized method to demonstrate adequate sensitivity for ADAs against both biosimilar and reference products, nor is there consensus on the type(s) of positive control to be used.

Postmarketing immunogenicity assessment

- Collection of immunogenicity data must continue in the real-world setting.

- To assign postmarketing safety events to the correct biologic, product nomenclature conventions must be followed for full traceability.

- Immunogenicity should also be monitored closely in real-world studies where patients on stable treatment with a reference biologic are switched to a biosimilar.

- Currently, immunogenicity data from switching studies are limited, especially for oncological indications.

Conclusion

- Comparative immunogenicity results must be understood by regulators and physicians in the context of the assays and population(s) used and their associated limitations.

- Further efforts are required to standardize comparative immunoassays. 


\section{Future perspective}

A number of anticancer biosimilars are under development and expected to enter clinical use in the near future. As bioanalytical platforms for detecting unwanted immune responses against biologics continue to advance, regulators must stay abreast of these developments in order to accurately interpret the risk of immune responses associated with biologic treatments, including biosimilars. Clinicians must also be aware of the relevance of evolving immunogenicity tests when choosing from an ever-increasing pool of biologic therapies. In addition to standardization of regulatory requirements for comparative immunogenicity assessments of biosimilars, future accumulation of real-world and fully traceable pharmacovigilance data should facilitate the evaluation of the potential risks and benefits of a biosimilar treatment.

\section{Author contributions}

All authors contributed equally to the manuscript and all approved the final article.

Financial \& competing interests disclosure

T Schreitmüller, A Zharkov and G Bakalos are F Hoffmann-La Roche Ltd employees; B Barton is a contractor at F Hoffmann-La Roche Ltd. The authors have no other relevant affiliations or financial involvement with any organization or entity with a financial interest in or financial conflict with the subject matter or materials discussed in the manuscript apart from those disclosed.

Medical writing support was provided by J Hanley (SFL Regulatory Affairs \& Scientific Communication, Switzerland) and funded by F Hoffmann-La Roche Ltd.

\section{Open access}

This work is licensed under the Attribution-NonCommercial-NoDerivatives 4.0 Unported License. To view a copy of this license, visit http://creativecommons.org/licenses/by-nc-nd/4.0/

\section{References}

Papers of special note have been highlighted as: $\bullet$ of interest; $\bullet \bullet$ of considerable interest

1 Kirchhoff CF, Wang XM, Conlon HD, Anderson S, Ryan AM, Bose A. Biosimilars: key regulatory considerations and similarity assessment tools. Biotechnol. Bioeng. 114(12), 2696-2705 (2017).

2 Blandizzi C, Galeazzi M, Valesini G. Transitioning from first- to second-generation biosimilars: an appraisal of regulatory and post-marketing challenges. Pharmacol. Res. 128, 306-314 (2017).

3 EMA. Guideline on Immunogenicity assessment of therapeutic proteins (EMEA/CHMP/BMWP/14327/2006 Rev 1) (2017). www.ema.europa.eu/docs/en_GB/document_library/Scientific_guideline/2017/06/WC500228861.pdf

-• Key regulatory guideline issued by the European Medicines Agency regarding the conduct of immunogenicity assessments for biologics, including biosimilars.

4 FDA. Guidance on Scientific considerations for demonstrating biosimilarity to a reference product (2015). www.fda.gov/downloads/drugs/guidancecomplianceregulatoryinformation/guidances/ucm291128.pdf

-• Key regulatory guideline issued by the US Food and Drug Administration regarding quality, nonclinical and clinical considerations for assessment of biosimilarity.

5 WHO Expert Committee on Biological Standardization. Guideline on evaluation of similar biotherapeutic products (SBPS) (2009). www.who.int/biologicals/areas/biological_therapeutics/BIOTHERAPEUTICS_FOR_WEB_22APRIL2010.pdf

-• Key regulatory guideline issued by the World Health Organization regarding quality, nonclinical and clinical considerations for assessment of biosimilarity.

6 EMA. Immunogenicity of biological therapeutics (2016). www.ema.europa.eu/docs/en_GB/document_library/Presentation/2016/03/WC500203438.pdf

7 FDA. The immunogenicity of therapeutic proteins-what you don't know can hurt YOU and the patient (2014). www.fda.gov/downloads/Drugs/DevelopmentApprovalProcess/SmallBusinessAssistance/UCM408709.pdf

8 Kuriakose A, Chirmule N, Nair P. Immunogenicity of biotherapeutics: causes and association with posttranslational modifications. J. Immunol. Res. 2016, 1298473 (2016).

9 Ben-Horin S, Heap GA, Ahmad T, Kim H, Kwon T, Chowers Y. The immunogenicity of biosimilar infliximab: can we extrapolate the data across indications? Expert Rev. Gastroenterol. Hepatol. 9(Suppl. 1), 27-34 (2015).

- Highlights the relevance of differences in dosing schedules, timing of clinical sampling and patient immune status when considering extrapolation of immunogenicity data to other therapeutic indications.

10 Ratanji KD, Derrick JP, Dearman RJ, Kimber I. Immunogenicity of therapeutic proteins: influence of aggregation. J. Immunotoxicol. 11(2), 99-109 (2014). 
11 Wadhwa M, Knezevic I, Kang HN, Thorpe R. Immunogenicity assessment of biotherapeutic products: an overview of assays and their utility. Biologicals 43(5), 298-306 (2015).

12 EMA. Omnitrope EPAR-scientific discussion (2006). www.ema.europa.eu/docs/en_GB/document_library/EPAR_-_Scientific_Discussion/human/000607/WC500043692.pdf

13 Haag-Weber M, Eckardt KU, Horl WH, Roger SD, Vetter A, Roth K. Safety, immunogenicity and efficacy of subcutaneous biosimilar epoetin-alpha (HX575) in non-dialysis patients with renal anemia: a multi-center, randomized, double-blind study. Clin. Nephrol. 77(1), 8-17 (2012).

14 Praditpornsilpa K, Tiranathanagul K, Kupatawintu P et al. Biosimilar recombinant human erythropoietin induces the production of neutralizing antibodies. Kidney Int. 80(1), 88-92 (2011).

15 EMA. Guideline on similar biological medicinal products containing monclonal antibodies (EMA/CHMP/BMWP/403543/2010) (2012). www.ema.europa.eu/docs/en_GB/document_library/Scientific_guideline/2012/06/WC500128686.pdf

16 EMA. Guideline on similar biological medicinal products (2014). www.ema.europa.eu/docs/en_GB/document_library/Scientific_guideline/2014/10/WC500176768.pdf

17 EMA. Guideline on similar biological medicinal products containing biotechnology-derived proteins as active substance: non-clinical and clinical issues (EMEA/CHMP/BMWP/42832/2005 Rev1) (2014). www.ema.europa.eu/docs/en_GB/document_library/Scientific_guideline/2015/01/WC500180219.pdf

18 EMA. Guideline on similar biological medicinal products containing biotechnology-derived proteins as active substance: quality issues (revision 1) (EMA/CHMP/BWP/247713/2012) (2014).

www.ema.europa.eu/docs/en_GB/document_library/Scientific_guideline/2014/06/WC500167838.pdf

19 FDA. Quality considerations in demonstrating biosimilarity of a therapeutic protein product to a reference product (2015). www.fda.gov/downloads/Drugs/GuidanceComplianceRegulatoryInformation/Guidances/UCM291134.pdf

20 FDA. Clinical pharmacology data to support a demonstration of biosimilarity to a reference product (2016). www.fda.gov/downloads/drugs/guidancecomplianceregulatoryinformation/guidances/ucm397017.pdf

21 WHO. Guidelines on evaluation of monoclonal antibodies as similar biotherapeutic products (SBPs) (2016). www.who.int/biologicals/BS2290_mAb-SBP_DB_Kai_LINE_NOs_20_July_2016.pdf

22 Dougherty MK, Zineh I, Christl L. Perspectives on the current state of the biosimilar regulatory pathway in the United States. Clin. Pharmacol. Ther. 103(1), 36-38 (2018).

23 Knezevic I, Griffiths E. WHO standards for biotherapeutics, including biosimilars: an example of the evaluation of complex biological products. Ann. NY Acad. Sci. 1407(1), 5-16 (2017).

24 FDA. Guidance on immunotoxicology evaluation of investigational new drugs (2002). www.fda.gov/downloads/drugs/guidancecomplianceregulatoryinformation/guidances/ucm079239.pdf

25 FDA. Guidance on immunogenicity assessment for therapeutic protein products (2014). www.fda.gov/downloads/drugs/guidances/ucm338856.pdf

26 FDA. Draft guidance on assay development and validation for immunogenicity testing of therapeutic protein products (2016). www.fda.gov/downloads/Drugs/GuidanceComplianceRegulatoryInformation/Guidances/UCM192750.pdf

27 EMA. Assays and strategies for immunogenicity assessment (2009). www.ema.europa.eu/docs/en_GB/document_library/Presentation/2009/11/WC500011068.pdf

28 Pineda C, Castaneda Hernandez G, Jacobs IA, Alvarez DF, Carini C. Assessing the immunogenicity of biopharmaceuticals. BioDrugs 30(3), 195-206 (2016).

29 EMA. Flixabi EPAR (2016). www.ema.europa.eu/docs/en_GB/document_library/EPAR___Public_assessment_report/human/004020/WC500208358.pdf

30 Kurki PCBWp. Novel aspects of the latest EMA immunogenicity guideline. 2017 EIP and ABIRISK meeing [presentation] (2017). www.e-i-p.eu/wp-content/uploads/2018/01/pekka_kurki.pptx

31 Gunn GR 3rd, Sealey DC, Jamali F, Meibohm B, Ghosh S, Shankar G. From the bench to clinical practice: understanding the challenges and uncertainties in immunogenicity testing for biopharmaceuticals. Clin. Exp. Immunol. 184(2), 137-146 (2016).

32 Ishii-Watabe A, Shibata H, Nishimura K et al. Immunogenicity of therapeutic protein products: current considerations for anti-drug antibody assay in Japan. Bioanalysis 10(2), 95-105 (2018).

33 Smith HW, Moxness M, Marsden R. Summary of confirmation cut point discussions. AAPS J. 13(2), 227-229 (2011).

34 Song S, Yang L, Trepicchio WL, Wyant T. Understanding the supersensitive anti-drug antibody assay: unexpected high anti-drug antibody incidence and its clinical relevance. J. Immunol. Res. doi: 10.1155/2016/3072586 (2016).

35 NIBSC. 1st WHO Erythropoietin Antibody Reference Panel - instructions for use (2016). www.nibsc.org/documents/ifu/15-240.pdf

36 Islam R. Bioanalytical challenges of biosimilars. Bioanalysis 6(3), 349-356 (2014).

37 Ryding J, Stahl M, Ullmann M. Demonstrating biosimilar and originator antidrug antibody binding comparability in antidrug antibody assays: a practical approach. Bioanalysis 9(18), 1395-1406 (2017). 
-• Highlights the challenges of developing head-to-head biosimilar versus reference product immunoassays. The authors describe a suggested, experience-based method for validation of the one-assay approach.

38 Emery P, Vencovsky J, Ghil J, Kang JW. Response to: 'Comparing the immunogenicity of the etanercept biosimilar SB4 with the innovator etanercept: another consideration' by Marshall et al. Ann. Rheum. Dis. 75(7), e38 (2016).

39 Emery P, Vencovsky J, Kang JW, Ghil J. Confirmation on the immunogenicity assay used in the SB4 Phase III study: response to the comments by Meacci et al. Ann. Rheum. Dis. 75(7), e40 (2016).

40 Emery P, Vencovsky J, Sylwestrzak A et al. A Phase III randomised, double-blind, parallel-group study comparing SB4 with Etanercept reference product in patients with active rheumatoid arthritis despite methotrexate therapy. Ann. Rheum. Dis. 76(1), 51-57 (2017).

41 Marshall L, Hickling T, Bill D, Mahgoub E. Comparing the immunogenicity of the etanercept biosimilar SB4 with the innovator etanercept: another consideration. Ann. Rheum. Dis. 75(7), e37 (2016).

42 Meacci F, Manfredi M, Infantino M, Grossi V, Benucci M. Anti Etanercept and anti SB4 antibodies detection: impact of the assay method. Ann. Rheum. Dis. 75(7), e39 (2016).

43 Chatterjee S, Vashishta L, Waichale VS et al. Development and validation of a cell based assay for the detection of neutralizing antibodies against recombinant insulins. J. Immunol. Methods 452, 53-62 (2018).

44 Gouty D, Cai CC, Cai XY et al. Recommendations for the development and validation of neutralizing antibody assays in support of biosimilar assessment. AAPS J. 20(1), 25 (2017).

-• Describes key challenges for the development of head-to-head neutralizing antibody assays. The authors provide recommendations for a one-assay approach.

45 Chamberlain P. Multidisciplinary approach to evaluating immunogenicity of biosimilars: lessons learnt and open questions based on 10 years' experience of the European Union regulatory pathway. Biosimilars 4, 23-43 (2014).

46 Cai XY, Thomas J, Cullen C, Gouty D. Challenges of developing and validating immunogenicity assays to support comparability studies for biosimilar drug development. Bioanalysis 4(17), 2169-2177 (2012).

47 Liu PM, Zou L, Sadhu C, Shen WD, Nock S. Comparative immunogenicity assessment: a critical consideration for biosimilar development. Bioanalysis 7(3), 373-381 (2015).

48 Richards S, Amaravadi L, Pillutla R et al. 2016 White Paper on recent issues in bioanalysis: focus on biomarker assay validation (BAV): (Part 3 - LBA, biomarkers and immunogenicity). Bioanalysis 8(23), 2475-2496 (2016).

49 EMA. Guideline on good pharmacovigilance practices (GVP). Product- or Population-Specific Considerations II: Biological medicinal products (2016). www.ema.europa.eu/docs/en_GB/document_library/Scientific_guideline/2016/08/WC500211728.pdf

- Guideline issued by the EMA concerning good pharmacovigilance practices for biologics. Safety reporting conventions, including reporting of brand names for attribution of postmarketing events to the correct product, are outlined.

50 FDA. Guidance on nonproprietary naming of biological products (2017). www.fda.gov/downloads/drugs/guidances/ucm 459987.pdf

- Guidance issued by the US FDA concerning nomenclature convention for biologics and traceability of postmarketing safety reports to the correct product.

51 Macdonald JC, Hartman H, Jacobs IA. Regulatory considerations in oncologic biosimilar drug development. MAbs 7(4), 653-661 (2015).

52 Klein K, Scholl JH, Vermeer NS et al. Traceability of Biologics in The Netherlands: an analysis of information-recording systems in clinical practice and spontaneous ADR reports. Drug. Saf. 39(2), 185-192 (2016).

53 Cheraghali A. Access to alternative biopharmaceuticals in low- and middle-income countries. GaBI J. 3(4), 164-165 (2014).

54 Kang HN, Knezevic I. Regulatory evaluation of biosimilars throughout their product life-cycle. Bull. World Health Organ. 96(4), 281-285 (2018).

55 IFPMA. Considerations for physicians on switching decisions regarding biosimilars (2017). www.if pma.org/wp-content/uploads/2017/03/Considerations-for-switching-decisions_IFPMA-vF.pdf

56 Declerck P, Bakalos G, Zintzaras E, Barton B, Schreitmuller T. Monoclonal antibody biosimilars in oncology: critical appraisal of available data on switching. Clin. Ther. 40(5), 798-809 (2018). 
